\title{
Time to ditch stand-alone stem cell oversight panels, experts say
}

Research involving human embryonic stem cells (hESCs) has always been a controversial subject in the US, but never more so as when George W. Bush was president. At the time, federal support for such research was limited to fewer than two dozen cell lines, and up through his first term in office, studies involving hESCs in the country were often conducted under a patchwork of inconsistent, and sometimes nonexistent, oversight.

To encourage responsible practices, the US National Academies issued a report in 2005 calling for the establishment of stand-alone institutional oversight committees, and within two years, at least 25 so-called 'embryonic stem cell research oversight committees', or ESCROs, cropped up across the country. Most of these were created voluntarily, except in the few states-California and Connecticut, as well as New York if the research is performed with state funding - that made the practice mandatory. Now, however, with hESC research widely practiced and accepted, some experts are questioning whether stand-alone ESCROs are still needed.

"As that early period of figuring out ways to implement good ethical guidelines has shifted into the more normal science of applying those concerns, the need for ESCROs has gotten smaller," says Henry Greely, a bioethicist at the Stanford Law School and chair of California's Human Stem Cell Research Advisory Committee. "It's not rocket science any more. A lot of [hESC research] is pretty routine, and it doesn't necessarily need a unique institution to deal with it."

In a commentary published in the January issue of the American Journal of Bioethics (13, 44-52, 2013), Greely argues that ESCROs were invaluable throughout the past decade because they kept early investigations involving hESCs above the ethical fray. Plus, they provided political cover for this contentious topic. However, the committees also came at a cost in the form of time, resources and manpower that could have been spent elsewhere, especially when studies involving human subjects were also being reviewed by institutional review boards (IRBs) and studies that used laboratory animals needed the approval of institutional animal care and use committees (IACUCs). Some protocols involving hESCs were even overseen by all three. "It may well make sense to cut down on the number of committees that people have to file applications to," Greely says.
Looking ahead, Greely contends that the vital role ESCROs have played in recent years can now be taken over by IRBs and IACUCsboth of which have existed at universities and research institutions for decades. Those two review bodies would only have to expand their remits slightly to cover hESC-specific considerations. For example, IACUCs would be tasked with weighing whether specific embryonic stem cell experiments might confer "human characteristics" to bioengineered animals, as well as enforcing the no-breeding requirements for chimeras dictated by the 2005 guidelines, both of which the IACUCs currently don't do.

Likewise, IRBs would have to consider cell line experiments that don't involve human subjects at all. "It's a bit of an extension of what IRBs have done," notes Greely, "but it should be within their comfort zone." Doing so, he asserts, would require little more than adding committee members with special expertise in stem cell research to handle the new oversight duties - a smaller burden, perhaps, than maintaining separate ESCROs.

"I'm very sympathetic to this view," says David Magnus, director of the Stanford Center for Biomedical Ethics and the editorin-chief of the American Journal of Bioethics. Magnus, who, together with Greely, sits on the Stanford Stem Cell Oversight Committee, argues that the ethical debates are now settled and that "anybody who's at least moderately sophisticated scientifically and ethically could be trained" to assess the validity of hESC research.

\section{Put it to a committee}

Julie Aultman, a bioethicist at Northeast Ohio Medical University in Rootstown, likes Greely's proposal-she's seen too many inconsistencies between ESCROs nationwide. However, she worries about filling in the expertise gap that would disappear. For that reason, she argues that the dissolution of ESCROs should coincide with the creation of a 'National Ethics Committee for Scientific Advancement' (Am. J. Bioeth. 13, 61-62, 2013). Such a committee would oversee all controversial emerging areas of research, not just the science of pluripotent stem cells-thereby eliminating the notion of hESC exceptionalism. By providing a direct resource and policy forum for institutional oversight panels, it could also offer more on-the-ground assistance than other national bodies such as the Presidential Commission for the Study of Bioethical Issues.
Not all ethicists agree with Greely's proposal, though. "I don't think the particular solution he provides is the right solution moving forward," says Jason Scott Robert, director of the Bioethics, Policy and Law Program at Arizona State University in Tempe. "If we were to transition to a model that relies on IRBs and IACUCs, we might jeopardize either the scientific progress or the careful oversight [provided by ESCROs], and I would rather not see either of those sacrificed."

"This is one of those areas where we have to be careful," adds Geoffrey Lomax, who oversees medical and ethical standards at the California Institute for Regenerative Medicine in San Francisco. Keeping ESCROs around, he maintains, is "conservative without really putting a lot of baggage on the research."

Unlike in the US, all research in Canada involving hESCs that is funded by that country's federal government or that takes place at an institution that receives federal support must be reviewed by a national ESCRO convened by the Canadian Institutes of Health Research (CIHR). Such research must additionally be approved by local IRBs and IACUCs where appropriate. (Canada uses different titles and acronyms for all these committees.)

John Williams, a medical ethicist at the University of Ottawa in Ontario who chaired the CIHR's Stem Cell Oversight Committee from 2007 to 2012, says that such a national policy, with its unique stem cell oversight body, helps ensure that federal granting agencies maintain the most up-to-date and scientifically informed regulations. "Over the years in reviewing protocols we have been faced with new questions that have been translated into changes in the guidelines," he says. "So, if the research protocols are dealt with simply at the local level, it would be pretty difficult to see how the policy issues would be kept up to date."

Ultimately, the decision to maintain ESCROs or not all comes down to a cost-benefit ratio, says Greely. Streamlining committee structures won't bring "enormous benefits," he admits, "but I don't think they're trivial benefits, and what are the benefits of continuing to have ESCROs after this breaking in and bureaucratization process has worked itself out? They're not very big."

"It's not saying these guys have been failures and we should get rid of them," he adds. "It's almost saying, "These guys have been so successful that they worked themselves out of a job'-and that's not a bad thing."

Elie Dolgin 